\title{
AS CORRELAÇÕES ENTRE TECNOLOGIA E A PERSPECTIVA FREIRIANA: APORTES PARA A SUPERAÇÃO DA EDUCAÇÃO HEGEMÔNICA
}

\author{
Monica Roberta Devai Dias ${ }^{1}$, Fernanda Pereira da Silva ${ }^{1}$, Adriana Aparecida de Lima Terçariol ${ }^{1}$, \\ Raquel Rosan Christino Gitahy². \\ ${ }^{1}$ Universidade Nove de Julho - UNINOVE, Programa de Pós-Graduação em Educação (PPGE), São Paulo, SP. \\ ${ }^{2}$ Universidade do Oeste Paulista - UNOESTE, Mestrado em Educação, Presidente Prudente, SP. E-mail: \\ atercariol@gmail.com
}

\section{RESUMO}

O objeto deste estudo foi a análise das relações entre tecnologia e a Pedagogia Freiriana, a partir de aportes bibliográficos. Discorreu-se sobre o uso das Tecnologias Digitais de Informação e Comunicação (TDIC) na escola - reiterando a importância do letramento digital ao sujeito contemporâneo, que deve se dar - por meio dos processos educativos propostos em ambientes educativos. Neste contexto, as concepções de Paulo Freire corroboram com o uso da tecnologia para propiciar educação equitativa e de qualidade a todos os partícipes do processo. Ressaltou-se, também, a importância da formação contínua - enquanto processo de integração e desenvolvimento da reflexão crítica sobre a prática docente, a partir da articulação das ferramentas tecnológicas às práticas pedagógicas.

Palavras-Chave: Tecnologias Digitais de Informação e Comunicação (TDIC), Formação de Professores, Perspectiva Freiriana, Letramento Digital.

\section{THE CORRELATIONS BETWEEN TECHNOLOGY AND THE FREIRIAN PERSPECTIVE: CONTRIBUTIONS TO THE EXECUTION OF HEGEMONIC EDUCATION}

\begin{abstract}
The object of this study was the analysis of the relations between technology and Freirian Pedagogy, based on bibliographical contributions. The use of Digital Information and Communication Technologies (TDIC) was discussed at school - reiterating the importance of digital literacy to the contemporary subject, which should be given - through educational processes proposed in educational settings. In this context, Paulo Freire's conceptions corroborate the use of technology to provide equitable and quality education to all participants in the process. It was also stressed the importance of continuous training - as a process of integration and development of critical reflection on teaching practice, from the articulation of technological tools to pedagogical practices.

Keywords: Digital Technologies of Information and Communication (TDIC), Teacher Training, Freirean Perspective, Digital Literacy.
\end{abstract}




\section{INTRODUÇÃO}

O ser humano, em seu processo sócio histórico, usou suas habilidades para vencer os obstáculos impostos pela natureza. Desta forma, desenvolveu e inventou instrumentos tecnológicos com o objetivo de superar dificuldades. Ao buscarmos o significado da palavra tecnologia identificaremos que ela é de origem grega. O prefixo "techne" significa "ofício" e o sufixo "logia" corresponde a "que diz". Assim, o termo 'tecnologia' é abrangente e envolve entre outros, o conhecimento técnico / científico e as ferramentas, processos e materiais criados e / ou utilizados a partir de tal conhecimento (HOUAISS, 2016).

A era digital transformou o modo como às pessoas vivem e se relacionam umas com as outras e com o mundo que as cerca e o ambiente escolar, mescla os nativos da era digital (estudantes e funcionários que nasceram na década de $1990^{1}$ ), aos antecessores dessa era (estudantes e funcionários que nasceram antes da década de 1990); os autores afirmam que essa miscigenação gera conflitos na escola. Aos educadores e demais funcionários, há a dúvida em como utilizar as ferramentas digitais no planejamento escolar; aos estudantes há a dúvida em como utilizá-las sem se dispersar com a sobrecarga de informações ou migrar para as redes sociais, colocando a aprendizagem em segundo plano.

Logo, um desafio para a educação contemporânea. A educação, segundo Morin (2007), deve apropriar-se das ferramentas tecnológicas, sobretudo a internet, que quando inserida no ambiente escolar, auxilia na aprendizagem, além de oportunizar a educação digital (letramento digital). Excluir o estudante dos meios digitais, em um mundo conectado, é mais um meio de elevar a desigualdade social. O termo analfabetismo digital é tema de discussões, não só de estudiosos pesquisadores da área, mas de educadores preocupados em inserir a tecnologia nas escolas para minimizar o fracasso escolar e as desigualdades.

Nessa perspectiva, o presente estudo apresenta uma análise das relações entre tecnologia e a Pedagogia Freiriana, a partir de aportes bibliográficos. Nesse sentido, discorre-se sobre o uso das Tecnologias Digitais de Informação e Comunicação (TDIC) em espaços educativos, enfatizando a sua importância para se promover a autonomia, o letramento digital, a superação de suas condições sociais, entre outros aspectos que promovam o desenvolvimento intelectual, social, político ao sujeito contemporâneo. Por fim, enfatiza-se ainda a relevância da formação docente, visando à articulação das TDIC aos processos educativos, adotando como uma referência uma perspectiva freiriana.

\section{METODOLOGIA}

Este estudo foi desenvolvido a partir de uma pesquisa bibliográfica. Para tanto, utilizou-se procedimentos específicos dessa categoria de pesquisa. A pesquisa bibliográfica foi desenvolvida com base em material já elaborado, constituído principalmente de livros e artigos científicos.

A principal vantagem da pesquisa bibliográfica reside no fato de permitir ao investigador a cobertura de uma gama de fenômenos muito mais ampla do que aquela que poderia pesquisar diretamente. Essa vantagem torna-se particularmente importante quando o problema de pesquisa requer dados muito dispersos pelo espaço. Por exemplo, seria impossível a um pesquisador percorrer todo o território brasileiro em busca de dados sobre população ou renda per capita; todavia, se tem a sua disposição uma bibliografia adequada, não terá maiores obstáculos para contar com as informações requeridas. A pesquisa bibliográfica também é indispensável nos estudos históricos. Em muitas situações, não há outra maneira de

\footnotetext{
${ }^{1}$ Nos Estados Unidos e na Europa a primeira geração digital nasce a partir de 1980.
} 
conhecer os fatos passados se não com base em dados bibliográficos (GIL, 2002, p. 45).

Porém, foram averiguadas as condições em que os dados foram coletados, analisou-se atentamente cada informação para identificar possíveis incoerências ou contradições. Após, estruturou-se a discussão dos temas apresentados a seguir.

\section{APRESENTAÇÃO DOS RESULTADOS - AS TECNOLOGIAS DIGITAIS DE INFORMAÇÃO E COMUNICAÇÃO EM SALA DE AULA}

As TDIC em sala de aula reestruturam o contexto de aprendizagem, efetuam a mediação das relações pedagógicas - sem barreiras temporais ou espaciais - implicam a reformulação do planejamento, da metodologia e da avaliação, isso porque favorecem várias ações simultâneas (SOFFNER; CHAVES, 2010). De acordo com Rojo e Moura (2012, p. 08), os suportes midiáticos propiciam o multiletramento quando caracterizadas por atividades que "[...] partem das culturas de referência do alunado (popular, local, de massa) e de gêneros, mídias e linguagens por eles conhecidos [...]", com o intuito de propor enfoques éticos, pluralistas e democráticos, permitindo que o sujeito "[...] amplie seu repertório cultural, na direção de outros letramentos, valorizados ou desvalorizados". A aula multiletrada - possibilita a imersão em letramentos críticos - o sujeito ao protagonizar suas ações na aprendizagem desenvolverá critérios, mecanismos de análise e metalinguagem com autonomia.

Palfrey e Gasser (2011) afirmam que os educadores possuem duas opções - ou ignoram o que é ótimo na rede e na maneira como os jovens a utilizam; ou escolhem utilizá-la e encaminhar todos para a era digital. Em ambiente virtual a construção do conhecimento é atribuída à necessidade de aprender, o estudante é desafiado, a atingir dentro de suas especificidades, resposta para os problemas propostos, a curiosidade o impulsiona, ele aprende por interesse. Neste viés, Freire $(2014$, p.33) ressalta que "[...] só existe saber na invenção, na reinvenção, na busca inquieta, impaciente, permanente, que os homens fazem no mundo, com o mundo e com os outros. Busca esperançosa também".

A interatividade e a mediação do professor proporcionam esse movimento dialógico - que vivifica na sala de aula, o desenvolvimento da leitura de mundo e o desenvolvimento da consciência cidadã, pois o sujeito tem a possibilidade de comunicar-se em tempo real com outros, que não só pertence à cultura local. Reconhecer e respeitar a identidade de cada um, propor soluções em conjunto e manter diálogo com o mundo é, também, se posicionar como cidadão do mundo.

O movimento dialógico que as ferramentas digitais oportunizam, concomitante a mediação do professor, coloca os sujeitos como partícipes nas tomadas de decisão de forma igualitária. A relação aluno-professor ocorre de modo horizontal, o estudante contemporâneo deixa de ser a representação de "[...] algo vazio a ser preenchido [...]" e o educador deixa de ser o mero transmissor. A relação educando-educador se opera nos moldes reflexivos.

O aluno e o professor refletem as condições que os cercam e juntos aprendem a trabalhar com a sobrecarga de informações impostas pelas mídias, e por meio da conscientização e pesquisa/estudo, observam os suportes tecnológicos para distinguir fato de boato; imposições de opiniões; assim se tornam indivíduos com real opção de escolha, dentre as mais variadas informações que sobrecarregam as diversas mídias (PALFREY; GASSER, 2011, p. 18).

A relação dialógica, ainda, permite que os envolvidos no processo sejam atuantes para reorganizar a sociedade, por meio do diálogo que "[...] é sempre comunicação [...] o diálogo não impõe, não maneja, não domestica, não sloganiza" (FREIRE, 1996, p. 67). Por isso, cabe ao professor, definir com clareza, quais ferramentas usar em aula - para quê e como.

O planejamento reflexivo das propostas didáticas devem embasar os pressupostos da 
conscientização cidadã, não como "[...] receptáculo inativo dos benefícios outorgado pelo Estado, que nada tem a dizer sobre as dimensões políticas e públicas", as atividades realizadas que envolvem as TDIC devem enfatizar ao estudante que diferentes tipos de direitos convivem, permeando pelos mais tradicionais e nem sempre cumpridos (como os que regem a CLT, por exemplo), aos mais recentes (como os direitos ao meio ambiente, por exemplo). (BOTELHO; SCHWARCZ, 2012, p.14).

Neste processo, a internet e as mídias veiculam as vozes hegemônicas do mundo, contudo se bem utilizadas, também, dão a voz e vez aos sujeitos, em igual escala, são ferramentas que servem a luta contra hegemônica, agindo em prol das igualdades sociais. Conforme Freire (2005 p. 66) "[...] o respeito à autonomia e à dignidade de cada um é um imperativo ético e não um favor que podemos ou não conceder uns aos outros". Por isso, as aulas, devem privilegiar o despertar da consciência crítica em relação à história, ao mundo e a si próprio - condição sine qua non - para que o sujeito adquira autonomia libertadora.

\section{DISCUSSÃO DOS RESULTADOS - A FORMAÇÃO DE PROFESSORES E O USO DAS TDIC EM CONTEXTOS EDUCACIONAIS EM UMA PERSPECTIVA FREIRIANA}

Desde que as TDIC começaram a fazer parte do cotidiano escolar, os educadores tiveram que rever suas formas de educar. Considerado por muitos especialistas, o uso das tecnologias em sala de aula, é um caminho sem volta, o educador passa a ser muito mais que um repassador de conhecimentos. Como afirma Morin (2007), as tecnologias de comunicação não substituem o professor, mas modificam algumas de suas funções

Reconhece-se a necessidade da apropriação, pelos educadores, dos avanços científicos e do conhecimento humano que possam contribuir para a qualidade da escola que se quer, e por meio da práxis humana alcançar a revolução em prol das classes oprimidas. O professor é a figura que assegura ao estudante efetivar sua aprendizagem em sala de aula. De acordo com Freire (2014, p.33), é o mediador do conhecimento, que estimula o pensamento estudantil, por meio de "[...] atos comunicantes, co-participativo [...] de modo que o próprio discurso teórico seja aliado à sua aplicação prática".

Democratizar a imersão ao mundo digital, por meio das TDIC em aula, permite o acesso ao mundo digital e, principalmente, como usar as diversas informações que veiculam nas mídias. Deste modo, é imperativo que o docente reveja princípios, conteúdos, metodologias e práticas para que contribua com a emancipação do educando.

Contudo, essa imersão de acordo com Palfrey e Gasser (2011), gera conflitos em educadores que se preocupam com o fato de estarem em descompasso com os alunos da era digital, o que os tornaria obsoletos com as mudanças no ambiente escolar (provindo do uso das TDIC), daí decorrem os receios e a resistência em utilizar as mídias digitais. Por meio da formação contínua o educador tem condições de escolher quais ferramentas usar, quando usar e como usar.

A prática docente exige do professor pesquisa contínua, assim ele encaminhará a prática pedagógica para o campo científico, fomentando uma racionalidade que lhe é própria, mas que só ressoa cotidianamente, quando o docente assume a postura epistemológica e atua como pesquisador. Só desse modo, é que será sujeito do saber, e mediará o conhecimento pelo diálogo, estabelecido na relação entre ele, educando e saber, conforme preceitua Freire $(2005$, p. 25), “[...] ensinar não é transferir conhecimento, mas criar possibilidades para a sua produção ou sua construção". A reformulação dos atos pedagógicos faz-se necessária para não incidir na educação bancária:

Em lugar de comunicar-se, o educador faz "comunicados" e depósitos que os educandos, meras incidências, recebem pacientemente, memorizam e repetem. Eis aí a concepção "bancária" da educação, em que a única margem de ação que se oferece aos educandos é a de receberem os 
depósitos, guardá-los e arquivá-los. Margem para serem colecionadores ou fichadores das coisas que arquivam. No fundo, porém, os 2410 grandes arquivados são os homens, nesta (na melhor das hipóteses) equivocada concepção "bancária" da educação. Arquivados, porque, fora da busca, fora da práxis, os homens não podem ser. Educador e educandos se arquivam na medida em que, nesta destorcida visão da educação, não há criatividade, não há transformação, não há saber (FREIRE, 1987, p. 33).

Neste contexto, as TDIC podem auxiliar a reverter à educação bancária, para a emancipação da educação progressista, pois imbrica o acesso à informação aos diálogos entre a cultura valorizada, a cultura periférica e os conhecimentos locais e globais dos alunos, como geradores de sentido e de aprendizagem - a figura docente - não é mero transmissor/reprodutor de conhecimento, torna-se o mediador da pesquisa, escrita/leitura e conhecimento. (ROJO; MOURA, 2012, p. 94).

Segundo Bourdieu (2007, p. 22) o docente traz para a prática pedagógica seu habitus e seu capital cultural e esses interferem em sua forma de trabalhar, deste modo, carrega elementos que Ihe proporciona condições para intervir em sua prática - essas condições para o autor "[...] são os princípios geradores [...] distintos e indistintos". Logo, subentende-se que o profissional carrega em si uma "[...] proporção silenciosa da ação pedagógica [...] constrói o espaço social, essa realidade invisível, que não podemos mostrar nem tocar é que organiza as práticas e as representações dos agentes".

O confronto entre os dois modelos de aprendizagem, enriquece a formação humana do docente, já que se desmembram intrínsecos e dignos de valor. Para Freire (2005, p. 38) "[...] na formação permanente dos professores, o momento fundamental é o da reflexão crítica sobre a prática. É pensando criticamente a prática de hoje ou de ontem que se pode melhorar a próxima prática" (FREIRE, 2002, p. 38). A educação libertadora que gera oportunidades provê da pesquisa, da ação epistemológica - quando o professor se entender como sujeito histórico em constante processo de construção, igualmente como seu aluno, promoverá a educação emancipatória.

A formação contínua também é importante, para que o docente estabeleça as relações entre plano de aula, sala de aula, identidade do sujeito. Para Sacristán (1997) as relações entre plano de aula/ sala de aula e construção identitária do sujeito devem embasar-se na cultura da coletividade. $\mathrm{O}$ autor alega que essa condição apesar de ser óbvia não é simples, já que perpassa pelo conceito do que é material e ideal. A formação contínua, faz-se necessário para minimizar a hegemonia dominante, que atua nos suportes tecnológicos, sobretudo nas mídias que manipulam as informações de acordo com sua ideologia, é fundamental conhecer/pesquisar, refletir criticamente tudo o que é fornecido pelas mídias, só assim, o sujeito deixará de ser manipulado. Além disso, o uso das TDIC em aula precisa levar o estudante a autonomia e emancipação, e por isso, não pode ocorrer nos moldes tecnicistas que visam a atender as necessidades do mercado.

Refletir sobre hegemonia e contra hegemonia, pontua Fontes (2008, p. 145), “[...] pressupõe analisar os modos de convencimento, de formação e de pedagogia, de comunicação e de difusão de visões de mundo, as sociabilidades peculiares, as maneiras de serem coletivas, as clivagens e as contradições presentes em cada período histórico".

Ressalta que a hegemonia dos grupos dominantes pode ser combatida com a contra hegemonia, na medida em que ocorre a superação da condição de subalternidade. Gramsci (1979, p. 314-315) situa as ações contra hegemônicas como "[...] instrumentos para criar uma nova forma ética política". Assim, usar os suportes midiáticos para transformar a sociedade é, também, formular ações contra hegemônicas, que ultrapassaram os muros escolares, já que a rede promove repercussão em escola global, e em muitos casos em tempo real. A formação contínua propiciará ao docente escolher quais mecanismos usar para mudar sua práxis, conferindo-lhe 
recursos para atuar em prol das classes menos favorecidas.

\section{CONCLUSÃO}

Ao usar a tecnologia em aula com base nos pressupostos freirianos é necessário empregar na ação educativa o caráter de práxis tecnológica, já que todas as decisões tomadas para formular as aprendizagens são, a priori, imbuídas de ideologias. É necessário que o docente aprenda a trabalhar com esses suportes, por meio da formação contínua para transformar o ambiente escolar em lugar emancipatório e equitativo. Assim, conseguirá justificar o uso das TDIC no intuito de oportunizar consciência cidadã e letramento digital, que visam a levar o sujeito a protagonizar suas ações.

Do ponto de vista epistemológico o uso dos suportes em aula decorre da concepção de mundo e do homem, a qual a sociedade está inserida e para Freire (2006) o docente necessita ter a compreensão real do 'porquê' utiliza determinada ferramenta, já que essas tecnologias são sobrecarregadas de manipulação político-ideológica da classe dominante.

A figura docente deve conscientizar-se que não há docência sem discência, "[...] as duas se explicam e seus sujeitos, apesar das diferenças que os conotam, não se reduzem à condição de objeto, um do outro". Portanto, as práticas pedagógicas necessitam dialogar com o respeito ao heterogêneo, Freire $(2014$, p.38) ressalta que "[...] quem ensina aprende ao ensinar e quem aprende ensina ao aprender".

\section{REFERÊNCIAS}

BARROS, D. M. V. Educação à distância e o universo do trabalho. Bauru: Educ, 2003.

BOURDIEU, P. A Reprodução: sistema de ensino. Petrópolis: Vozes, 2007.

FONTES, V. Intelectuais e mídia - quem dita à pauta? In: COUTINHO, Eduardo Granja (Org.). Comunicação e contra hegemonia: processos culturais e comunicacionais de contestação, pressão e resistência. Rio de Janeiro: Editora UFRJ, 2008. p. 145-161.

FREIRE, P. Pedagogia da autonomia: saberes necessários à prática educativa. São Paulo: Paz e Terra, 1996. (Leitura).

. Pedagogia da Esperança: Um reencontro com a pedagogia do oprimido. Rio de Janeiro: Paz e Terra, 2014. (1992). . Pedagogia do Oprimido. Rio de Janeiro: Paz e Terra, 2005.

Gil, A. C. Como elaborar projetos de pesquisa. - 4. ed. - São Paulo: Atlas, 2002.

GRAMSCI, Antonio. Os intelectuais e a organização da cultura. Rio de Janeiro: Civilização Brasileira, 1979.

HOUAISS, A. Etimologia das palavras, 2016. Disponível em:

<https://houaiss.uol.com.br/pub/apps/www/v2-3/html/index.htm\#0>. Acesso em: 28. Nov. 2016. MORAN, J. Novas Tecnologias e Mediação Pedagógica. São Paulo: Papirus: 2007.

ROJO, R; MOURA, E. Multiletramentos na escola. São Paulo: Parábola, 2012.

SACRISTÁN, J. G. Poderes instáveis em educação. Porto Alegre: Artes Médicas, 1997. 
SARAIVA, T. Educação à distância no Brasil: ligações da história. In: Em aberto, Brasília, ano 16, n. 70, p. 17-27, abr./jun.1996.

SOFFNER, R. Tecnologia e educação: um diálogo Freire - Papert. Tópicos Educacionais - UFPE, Recife, v.19, n.1, jan/jun. 2013

SOFFNER, R; CHAVES, E. O. C. Tecnologia, ambientes de aprendizagem e Educação Não-Formal. Revista de Ciências da Educação UNISAL- Americana/SP, ano XII, n. 22, 2010, p. 493-512.

PALFREY, J; GASSER, U. Nascidos na era digital: entendendo a primeira geração de nativos digitais. Porto Alegre: Grupo A, 2011. 